\title{
Modelling the impact of MAUP on environmental drivers for Schistosoma japonicum prevalence
}

\author{
Andrea L. Araujo Navas ${ }^{1 *}$, Frank Osei ${ }^{1}$, Ricardo J. Soares Magalhães ${ }^{2,3}$, Lydia R. Leonardo ${ }^{4}$ and Alfred Stein ${ }^{1}$
}

\begin{abstract}
Background: The modifiable areal unit problem (MAUP) arises when the support size of a spatial variable affects the relationship between prevalence and environmental risk factors. Its effect on schistosomiasis modelling studies could lead to unreliable parameter estimates. The present research aims to quantify MAUP effects on environmental drivers of Schistosoma japonicum infection by (i) bringing all covariates to the same spatial support, (ii) estimating individuallevel regression parameters at $30 \mathrm{~m}, 90 \mathrm{~m}, 250 \mathrm{~m}, 500 \mathrm{~m}$ and $1 \mathrm{~km}$ spatial supports, and (iii) quantifying the differences between parameter estimates using five models.

Methods: We modelled the prevalence of Schistosoma japonicum using sub-provinces health outcome data and pixel-level environmental data. We estimated and compared regression coefficients from convolution models using Bayesian statistics.

Results: Increasing the spatial support to $500 \mathrm{~m}$ gradually increased the parameter estimates and their associated uncertainties. Abrupt changes in the parameter estimates occur at $1 \mathrm{~km}$ spatial support, resulting in loss of significance of almost all the covariates. No significant differences were found between the predicted values and their uncertainties from the five models. We provide suggestions to define an appropriate spatial data structure for modelling that gives more reliable parameter estimates and a clear relationship between risk factors and the disease.

Conclusions: Inclusion of quantified MAUP effects was important in this study on schistosomiasis. This will support helminth control programmes by providing reliable parameter estimates at the same spatial support and suggesting the use of an adequate spatial data structure, to generate reliable maps that could guide efficient mass drug administration campaigns.
\end{abstract}

Keywords: Schistosomiasis modelling, Modifiable areal unit problem, Uncertainty, Bayesian statistics, Convolution model

\section{Background}

Schistosomiasis $(\mathrm{SCH})$ is a water-borne neglected tropical disease of public health significance [1] associated with important morbidity outcomes in school-aged children such as malnutrition, anaemia and stunted growth

\footnotetext{
*Correspondence: a.l.araujonavas@gmail.com

${ }^{1}$ Faculty of Geo-information Science and Earth Observation (ITC), University of Twente, PO Box 217, 7500 AE Enschede, The Netherlands

Full list of author information is available at the end of the article
}

in school-aged children [2, 3]. Infection is caused by skin penetration of the cercariae, the larval infective stage of the parasite, also known as schistosome. Three schistosome species cause the infection: Schistosoma japonicum, S. mansoni and S. haematobium. Due to its zoonotic life-cycle [4], S. japonicum is the hardest to control; its infection life-cycle includes the amphibious snail Oncomelania hupensis as the intermediate host, and humans and other mammalians as definite hosts $[5,6]$.

c) The Author(s) 2020. This article is licensed under a Creative Commons Attribution 4.0 International License, which permits use, sharing, adaptation, distribution and reproduction in any medium or format, as long as you give appropriate credit to the original author(s) and the source, provide a link to the Creative Commons licence, and indicate if changes were made. The images or other third party material in this article are included in the article's Creative Commons licence, unless indicated otherwise in a credit line to the material. If material is not included in the article's Creative Commons licence and your intended use is not permitted by statutory regulation or exceeds the permitted use, you will need to obtain permission directly from the copyright holder. To view a copy of this licence, visit http://creativecommons.org/licenses/by/4.0/. The Creative Commons Public Domain Dedication waiver (http://creativecommons.org/publicdomain/zero/1.0/) applies to the data made available in this article, unless otherwise stated in a credit line to the data. 
SCH affects more than 252 million people worldwide [7] especially populations living in poor conditions, where access to clean water and sanitation is limited.

Traditionally, SCH is controlled by the use of anthelminthic drugs in at-risk populations [8]. Mass drug administration campaigns identify at-risk populations by using $\mathrm{SCH}$ risk mapping. $\mathrm{SCH}$ mapping uses geographical information systems (GIS), global positioning systems and remotely sensed environmental data $[9,10]$. Modelling those infections using various statistical methods have enabled the study of the distribution of populations at-risk $[9,10]$, and the role of the environmental variation on the geographical heterogeneity of infection burden (i.e. prevalence or intensity of infection) [11]. Statistical modelling of $\mathrm{SCH}$ quantifies empirical relationships between indirect morbidity indicators of public health significance and environmental risk factors. Those could be extracted from Earth Observation (EO) data such as monitor sites or satellite imagery. In addition, EO data help to interpolate the level of infection towards unsampled locations [12-14].

The robustness of $\mathrm{SCH}$ geographical modelling efforts is affected by uncertainties propagated from the use of EO data at various spatial and temporal scales of analysis [15]. EO data are generally constrained by their spatial and temporal scale of sampling [16]. In this study, we focus on spatial scale. Scale is a major concern in spatial epidemiology $[17,18]$ since it determines the significance of the various environmental risk factors on the disease distribution [19]. Spatial scale encompasses the spatial support and the spatial extent of analysis [20]. The spatial support refers to the area that each individual observation occupies in space. In the case of a raster grid, the spatial support is the spatial resolution (e.g. a $30 \times 30$ $\mathrm{m}$-resolution Landsat pixel). The spatial extent is the spatial coverage of a set of observations (e.g. administrative units) and is gathered following a sampling scheme [20]. For a given extent, the support size and shape of spatial units may affect the patterns identified in the survey and environmental data $[21,22]$ and the relationship between the disease morbidity indicators and the environmental risk factors. This is known as the modifiable areal unit problem (MAUP) [23, 24]. The MAUP arises because spatial units of analysis are often created using different ad hoc shapes and sizes. Statistical analyses of data performed according to these varying spatial units may lead to different results (e.g. correlation and regression coefficients) [24].

Various studies investigated the consequences of ignoring MAUP effects in spatial epidemiological modelling. For instance, Hellsten et al. [25] studied the influence of using aggregated covariate data to model ammonia emissions at the farm level. They showed that the size and shape of spatial aggregation areas strongly affect the location of the emissions estimated by the model, e.g. too small areas resulting in false emission "hot spots". Schur et al. [21] and Schur et al. [22] aggregated $\mathrm{SCH}$ prevalence maps to estimate endemicity for various administrative units [26]. Such aggregation showed different patterns of endemicity and intervention approaches. As a consequence, localized areas of high endemicity may not be addressed properly. In a recent study [27], we quantified the effect of pure specification bias, that originates when using group-level (i.e. aggregated) survey data at an administrative level for individual-level inferences. Equation 1 shows the common method used to model schistosomiasis. Data on the human S. japonicum infection variable $y$ are commonly aggregated at barangay $k$ level, $y_{k}$ has a binomial distribution with parameters $N_{k}$ and $p_{k}$ corresponding to the number of sampled individuals and the probability of infection, respectively. Parameters for this distribution are obtained from the mean of various environmental risk factors within barangay $k$ as predictors, denoted as $\bar{x}_{k}$, where $\gamma$ are the barangay-level coefficients, $\gamma_{0}$ being the intercept and $\gamma_{(1 \ldots n)}$ the regression coefficients for $n$ environmental covariates (Eq. 1).

$$
\begin{aligned}
& y_{k} \mid \bar{x}_{k}, \gamma \sim \operatorname{Binomial}\left(N_{k}, \hat{p}_{k}\right) \\
& \operatorname{logit}\left(\hat{p}_{k}\right)=\gamma_{0}+\gamma_{1} \cdot \bar{x}_{2_{k}}+\gamma_{2} \cdot \bar{x}_{2_{k}}+\ldots+\gamma_{n} \cdot \bar{x}_{n_{k}}
\end{aligned}
$$

We calculated individual-level regression parameters by modifying Equation 1 into a convolution model. We observed differences ranging from -0.19 to 0.28 between individual (i.e. $\gamma$ coefficients) and group level parameter estimates and their uncertainties. High differences were observed for NDWI (0.28), LSTN $(-0.19)$ and LSTD (0.16). Although some covariates exhibited a less significant effect on schistosomiasis, uncertainties in their individual level coefficients were lower than the group-level regression coefficients (e.g. LSTD and elevation). We concluded that the choice of spatial support affects the model parameter estimates and their associated uncertainties by changing the within-covariates variability in exposure areas. The selection of spatial support should be further investigated as it might represent a significant source of uncertainty in $\mathrm{SCH}$ modelling [15].

Up to date, the majority of SCH studies have put little attention to the size of spatial support. They use EO data at various spatial supports with misaligned grids ignoring the possible consequences on the observed patterns of the data $[21,22]$. Moreover, MAUP effects on the various environmental risk factors used as drivers for $\mathrm{SCH}$ infection have not been quantified. This is important as the relevance of the environmental risk factors on $\mathrm{SCH}$ depends on the scale of analysis [7, 19]. Ignoring MAUP 
effects might produce unreliable predictions of at-risk populations, and consequently, wrong decisions based upon inefficient mass drug administration campaigns.

The purpose of this research is to quantify MAUP effects on environmental drivers of $S$. japonicum infection. To achieve this objective we aim to: (i) aggregate and disaggregate EO data in order to bring all covariates to a the same spatial support of analysis; (ii) estimate individual-level covariate regression parameters at $30 \mathrm{~m}$, $90 \mathrm{~m}, 250 \mathrm{~m}, 500 \mathrm{~m}$ and $1 \mathrm{~km}$ spatial supports, by using a convolutional model that accounts for pure specification bias; and (iii) quantify the differences between parameter estimates using five different models.

\section{Methods}

\section{Study area and data on human Schistosoma japonicum} infection

We use S. japonicum infection data collected as part of the 2008 Nationwide Schistosomiasis Survey in the Philippines. Here, S. japonicum is endemic in 28 of its 81 provinces [28], with approximately 1.8 million estimated infected people [29]. The disease affects children, adolescents, and individuals with high-risk occupations, such as farmers and fishermen $[29,30]$. The area of study is the region of Mindanao in the Philippines (Fig. 1). This area was selected due to the high response rate of $70.9 \%$ of the individuals to the 2008 survey [31, 32] and the good spatial coverage of the sampling.

A two-stage systematic cluster sampling was used where stratification was done using high, medium and low prevalence levels, obtained from the 1994 World Bank-assisted Philippine Health Development Programme. Provinces and sub-municipalities called barangays were the primary and secondary sampling units, respectively. A barangay is the smallest administrative division in the Philippines, numbering from 58 to 1158 within a single province. In total, 11 provinces with high $(\geq 2 \%)$ and medium $(0.091-1.99 \%)$ prevalence rates were included, while 9 low-prevalence $(0.04-0.09 \%)$ provinces were randomly selected. Within the selected provinces, barangays with high prevalence rates were surveyed. In total, between 2 and 10 barangays were surveyed per province, resulting in 108 out of 10,021 barangays that were surveyed in Mindanao.

For S. japonicum diagnosis, a Kato-Katz thick smear examination [32] was used based on a two-sample stool collection. However, due to inconsistencies in the second stool sample submission, only the results of the first sample were available [8]. Samples were taken from people aged two years and above and were analysed using a microscope. Active infection was indicated by the presence of $S$. japonicum eggs.

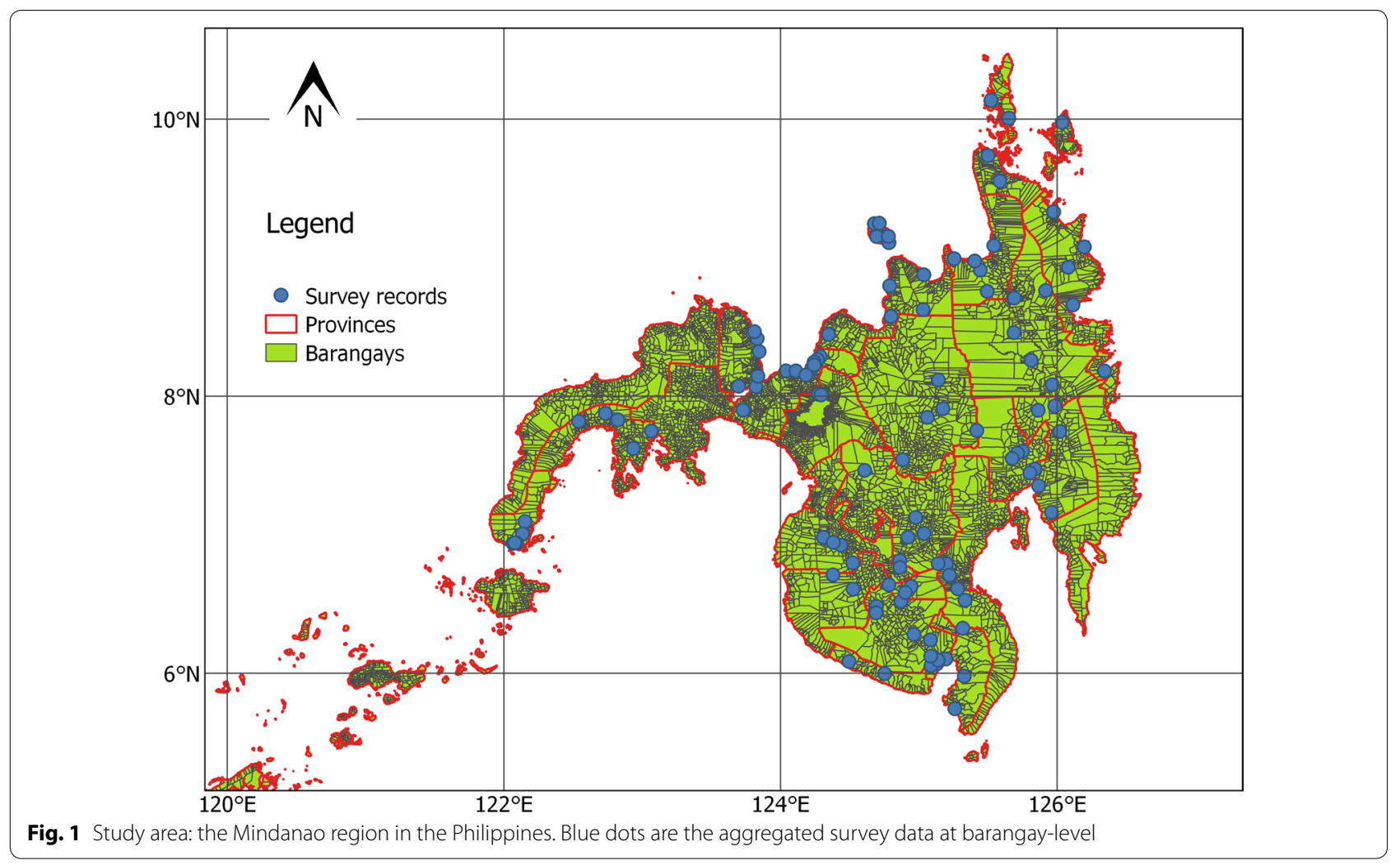


Data such as age and gender were recorded for 19,763 individuals. Barangay and province information for each individual was recorded but not georeferenced. For this reason, individual-level survey data were aggregated and geolocated to the centroids of the 108 barangays. We used a probability of infection in barangay $k$ as our disease outcome variable. We obtained an up-to-date barangay centroids shape file from DIVA geographical information system [33]. More details about the sampling design and surveyed information can be found in Leonardo et al. [31, 34].

\section{Environmental risk factors}

We included in our analysis six relevant environmental risk factors for $\mathrm{SCH}$ transmission $[35,36]$. These are the nearest distance to water bodies (NDWB), the normalized difference vegetation index (NDVI), the normalized difference water index (NDWI), land surface temperature at day (LSTD) and at night (LSTN), and elevation (E). NDWB shows the accessibility of people to water bodies that represent potential infection foci as they may contain contaminated snail hosts that release the infective larval stages of the parasite [8]. NDVI is and indicator of flooded vegetation [8], particularly rice-paddy fields, and environmental moisture [37, 38]. Both are an important risk factor for Asian SCH [39]. NDWI was used as a proxy indicator of flooding $[37,40]$ showing potentially hidden water bodies. LSTD and LSTN are determinant for the survival of snail larval stages $[41,42]$ and are used as proxies for water temperature given that the thermal condition of shallow waters usually reflects the ambient temperature of the air [8]. Elevation is relevant for $\mathrm{SCH}$ transmission as the local topography of the area determines the presence of snails [43, 44]. For instance, at lower altitudes the risk of finding snails increases.

NDWB values range from 0.17 to $26.2 \mathrm{~km}$ and were calculated using the closest facility network analysis tool from ArcGIS [45]. We used the river and road network, and the cities and hamlets locations as input for the network. Rivers and roads were extracted from the Open Street Map Project in the Philippines [46]. Cities and hamlet locations were obtained from the National Mapping and Resource Information Authority from The Philippines [47] data base from 2010. We calculated the nearest distance from each city and hamlet to a water body following a road and interpolated those values within all surveyed barangays towards a spatial support of $30 \mathrm{~m}$.

NDVI values range from 0 to 0.84 and were obtained from two sources of information, i.e. a series of Landsat 5 images from 2008 with a spatial support of $30 \mathrm{~m}$ and the MODIS MOD13Q1 product with a spatial support of $250 \mathrm{~m}$. NDWI values range from 0.06 to 0.61 and were also obtained from two sources of information, i.e. a Landsat 5 imagery product from 2008 with a spatial support of $30 \mathrm{~m}$ and the annual composite from Landsat 7 from 2008 derived from Google Earth Engine with a spatial support of $500 \mathrm{~m}$. LSTD values range from 297.77 to $309.52{ }^{\circ} \mathrm{K}$ and LSTN ranges from 289.73 to $297.29^{\circ} \mathrm{K}$. LSTD and LSTN values were derived from MODIS MOD11A2_LST product with a spatial support of $1 \mathrm{~km}$. Finally, elevation values range from 0 to 969.57 $\mathrm{m}$ was obtained from ASTER GDEM version 2 from USGS [48] with a spatial support of $30 \mathrm{~m}$. All covariates were set to a common coordinate system UTM zone $51 \mathrm{~N}$ and were standardized to have mean $=0$ and standard deviation $=1$ before being used. Table 1 summarizes all sources of information.

\section{Modifying the areal units of analysis}

From now onwards, we will refer to an area unit as the spatial support of analysis (SSA). We used five SSAs, with a spatial support equal to $30 \mathrm{~m}, 90 \mathrm{~m}, 250 \mathrm{~m}, 500 \mathrm{~m}$ and $1 \mathrm{~km}$, respectively. These spatial supports increase when going from low to high data aggregation. These values were selected based upon the commonly used spatial

Table 1 Environmental variables description

\begin{tabular}{|c|c|c|c|c|c|}
\hline $\begin{array}{l}\text { Environmental } \\
\text { variable }\end{array}$ & Spatial resolution & $\begin{array}{l}\text { Temporal } \\
\text { resolution }\end{array}$ & Data type & $\begin{array}{l}\text { Original coordinate } \\
\text { system }\end{array}$ & Data source \\
\hline Elevation & $30 m$ & na & Raster & EPSG:4326 & ASTER GDEM V2 from USGS \\
\hline \multirow[t]{2}{*}{ NDVI } & $250 \mathrm{~m}$ & 2008 & Raster & EPSG:4326 & MOD13Q1 \\
\hline & $30 \mathrm{~m}$ & 2008 & Raster & EPSG:4326 & Landsat 5 \\
\hline \multirow[t]{2}{*}{ NDWI } & $500 \mathrm{~m}$ & 2008 & Raster & EPSG:32651 & Landsat 7, 1-year composite \\
\hline & $30 m$ & 2008 & Raster & EPSG:4326 & Landsat 5 \\
\hline LST & $1 \mathrm{~km}$ & 2008 & Raster & EPSG:4326 & MOD11A2 \\
\hline NDWB & $250 \mathrm{~m}$ & 2010 & Raster & EPSG:32651 & $\begin{array}{l}\text { Derived from closest facility network using } \\
\text { roads, urban areas, river network and water } \\
\text { bodies }\end{array}$ \\
\hline
\end{tabular}


supports at which the environmental information is originally provided.

For NDVI, SSA $=30 \mathrm{~m}$, we obtained NDVI values from Landsat 5 images. Many of these images presented gaps due to the presence of clouds. These gaps were covered using disaggregated NDVI MODIS images at the Landsat resolution. Disaggregation was performed using a linear model that predicted NDVI Landsat values based on NDVI MODIS values. NDVI values were obtained by merging the original and predicted Landsat NDVI values. For $\mathrm{SSA}=90 \mathrm{~m}$, we aggregated the previously merged NDVI values using their mean. For SSA $=250 \mathrm{~m}$, we used the NDVI MODIS product directly. Finally, for SSA $=0.5$ and $1 \mathrm{~km}$, we aggregated the NDVI mean values from MODIS.

NDWI values were obtained from the Landsat 5 images. Gaps in some of these images were covered using disaggregated NDWI composite images at the Landsat resolution. Disaggregation towards SSA $=30 \mathrm{~m}$ was done by interpolating NDWI values using ordinary kriging. For SSA $=90 \mathrm{~m}$ and $250 \mathrm{~m}$, we aggregated the combined $30 \mathrm{~m}$ NDWI using its mean. For SSA $=500 \mathrm{~m}$, we directly used the Landsat 7 composite. Finally, for $S S A=1 \mathrm{~km}$, we aggregated the mean of the original Landsat 7 composite.

To obtain LSTD and LSTN values for SSA $=30 \mathrm{~m}$, we disaggregated the original MODIS values by using ordinary kriging interpolation. For $S S A=90 \mathrm{~m}, 250 \mathrm{~m}$ and $500 \mathrm{~m}$, we aggregated the previously interpolated values using their mean. For SSA $=1 \mathrm{~km}$, we used directly LSTD and LSTN from MODIS.

The interpolated NDWB values for $\mathrm{SSA}=30 \mathrm{~m}$ were used to obtain NDWB for SSA $=90 \mathrm{~m}, 250 \mathrm{~m}, 500 \mathrm{~m}$ and $1 \mathrm{~km}$ by aggregating the mean values. For elevation, we directly used the original $30 \mathrm{~m}$ SSA Aster images. For $\mathrm{SSA}=90 \mathrm{~m}, 250 \mathrm{~m}, 500 \mathrm{~m}$ and $1 \mathrm{~km}$, we aggregated the mean values of the original Aster images.

\section{Modelling Schistosoma japonicum infection under the MAUP \\ Convolution model}

We modelled human S. japonicum infection at the five increasing SSAs using a convolution model that accounts for pure specification bias [27]. Pure specification is a source of uncertainty $[11,49]$ that produces loss of information on the real relationship between the disease and the environmental covariate data, when using aggregated survey data in a non-linear model, for example, for individual-level inferences [50]. It is called 'pure' because it specifically addresses model specification bias [51], and it biases the estimates because any direct link between exposure and health outcomes is imperfectly measured [52]. This is because the regression function does not approximate the real relationship between the affected population and their exposure [27]. Pure specification bias can be reduced as the within area exposure is more homogenous [50]. This could be done by having a finer partition of space at which environmental risk factors are available [50, 53].

In this study, we propose to minimize and quantify pure specification bias by extracting covariate information from cities within barangays (Fig. 2) and by modelling the disease using a convolution model [53]. The city level is the finest available extent of analysis. Cities thus serve as a proxy for individual-level exposure locations. We identified all cities within the surveyed barangays using Google Earth Images. Available cities were extracted from the 2010 build-up data base from the National Mapping and Resource Information Authority of the Philippines [54]. We completed unavailable cities using Google Earth Images.

For the convolution model, we used the aggregate data method proposed by Prentice and Sheppard [55]. For each SSA, we obtained covariate information $x$ for image pixel $i$ belonging to a city $j$ within a specific barangay $k$ (Fig. 2). Let $n=6$ be the number of covariates $x_{i j k}$ measured at locations $s_{i j k} i=1, \ldots, m_{k}$ where $m_{k}$ denotes the number of city pixels within barangay $k$. Note that with an increasing resolution, the possibility increases that there are no pixel points falling in cities of the withinpixel sizes. Data on the human S. japonicum infection are available at individual-level recorded within a barangay $k$. Because the exact response locations of the individual-level data are unknown, we aggregated them to their corresponding barangay centroid, denoted by $y_{k}$. To estimate the average probability of infection of the individuals in barangay $k$ and the individual level coefficients $\beta$, we obtained the mean risk function $\hat{\hat{p}}_{k}$ over the total number of city pixels or exposure locations (Eq. 2). We accounted for the spatial variability at barangay-level by adding a spatial structure random effects term $s_{k}$. Pure specification bias results as $\gamma \neq \beta$ and is then minimized by using the individual-level regression coefficients $\beta$ instead of the group-level coefficients $\gamma$. The accompanying uncertainties are quantified by the difference between the group an individual-level credible intervals [27] for each SSA. The convolution model used is of the form:

$$
y_{k} \mid x_{i j k}, \beta \sim \operatorname{Binomial}\left(N_{k}, \hat{\hat{p}}_{k}\right)
$$

$$
\hat{\hat{p}}_{k}=\frac{1}{m_{k}} \cdot \sum_{i=1}^{m_{k}} \frac{1}{1+\exp \left(-\left(\beta_{0}+\beta_{1} \cdot x_{1_{i j k}}+\beta_{2} \cdot x_{2_{i j k}}+\ldots+\beta_{n} \cdot x_{n_{i j k}}+s_{k}\right)\right)} .
$$




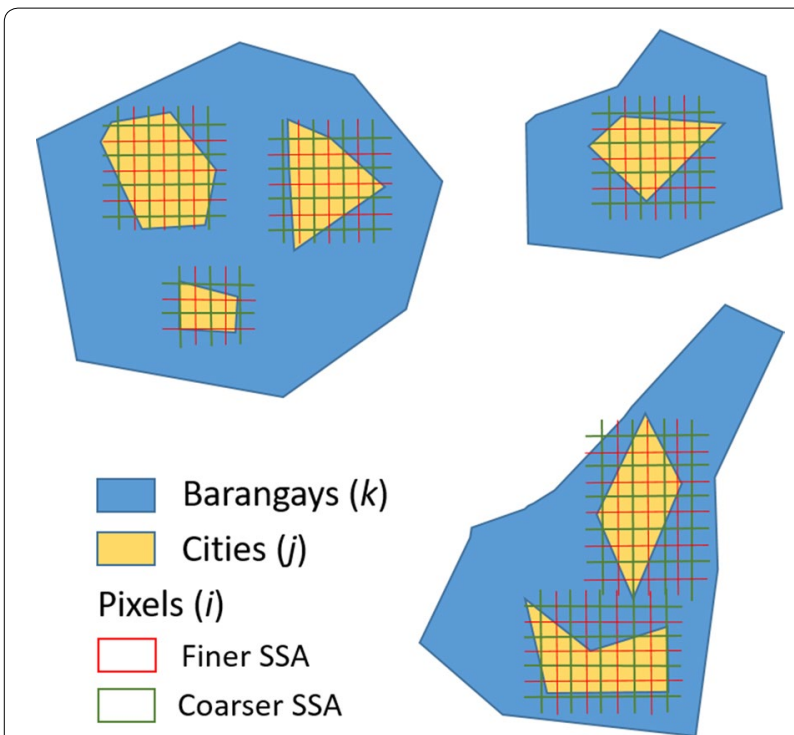

Fig. 2 Environmental risk factors extraction at pixel-level from cities within barangays

\section{Model implementation}

Five models were implemented, all including an intercept $\left(\beta_{0}\right)$, pixel-level environmental variables $\left(x_{i j k}=\mathrm{NDVI}\right.$, NDWI, LSTD, LSTN, E, NDWB) and their corresponding individual-level coefficients $\beta$. Collinearity between covariates was assessed with the Pearson's correlation coefficient. All covariates were standardized to have mean $=0$ and standard deviation $=1$.

The intercept $\beta_{0}$ was given a diffuse uniform prior distribution with wide bounds $\beta_{0} \sim U[-100,100]$. The other $\beta$ parameters were given a diffuse normal distribution $\beta \sim N\left[0, \frac{1}{\sigma^{2}}\right]$, with $\sigma$ uniformly distributed on a wide range of $\sigma \sim U[0,100]$. These distributions avoid overestimating the parameters [56] and allow a good sequences mixing used for Markov Chain Monte Carlo (MCMC) simulations, contributing to a fast convergence [57].

Prior information for the spatially structured random effects was based upon a geostatistical model that can be used as a sampling distribution for continuous spatial data [58]. The vector of random variables $s$ associated with point locations $\left(x_{k}, y_{k}\right), k=1, \ldots, K$, was modelled with a multivariate normal distribution $s \sim \operatorname{MVN}_{K}\left[\mu, \Sigma_{a b}\right]$ with a mean $\mu=0$ and a covariance matrix $\Sigma_{a b}=\sigma^{2} \cdot \exp \left[-\left(\phi \cdot d_{a b}\right)^{\kappa}\right]$ defined by a powered exponential spatial decaying correlation function.

The covariance matrix $\Sigma_{a b}$ is specified as a function of the distances $d_{a b}$ between barangay centroids $a$ and $b$, with the rate of decline of spatial correlation per unit of distance $\phi$, the scalar parameter representing the overall variance $\sigma^{2}$ and the scalar parameter $\kappa$ controlling the amount of spatial smoothing. Because extreme values of $\kappa(0$ and 2$)$ could lead to undesirable smoothing, we used $\kappa=1$. Prior information for $\phi$ was set to be uniform: $\phi \sim U\left[2 \mathrm{E} 10^{-7}, 3 \mathrm{E} 10^{-3}\right]$. These values give a diffuse but plausible prior range of correlations between 0.10.99 at the minimum distance between points $(575 \mathrm{~m})$ and between $0-0.3$ at the maximum distance between points $(<552 \mathrm{~km})$, assisting identifiability [59]. For $\sigma^{2}$, a half-normal distribution was selected: $\sigma^{2} \sim H N[0,1]$ to restrict the prior $\sigma^{2}$ to positive values and avoid problems with convergence $[56,60]$.

To run the model, we used three sequences or chains with 50,000 iterations. This number of iterations ensured that the simulations were representative of target distributions and a stable convergence [57]. In order to diminish the influence of starting values, we discarded the first half of each sequence [57] using a 'burn-in' of 25,000 iterations. Convergence was monitored visually and statistically by inspecting the trace plots, and by checking the $\hat{R}$ statistic $[61,62]$ also called the potential scale reduction factor. This potential scale reduction factor assesses sequences mixing by comparing the between and within variation. An $\hat{R}$ value $<1.1$ indicates evidence that sequences have converged [61], while higher values suggest that an increase in the number of simulations may improve the inferences [57].

Survey and environmental data were structured in a rectangular format where columns are headed by the array name. Survey data and the codes in BUGS for the various SSA are provided in Additional file 1: Table S1 and Additional file 2: Text S1, respectively.

\section{Model validation}

The five models were validated using two methods. The first method compared the data generated from the simulations of the predictive distribution to the observed data using a test statistic. A test statistic is a value derived from the sampled data and is used to perform hypothesis testing. This test statistic is the posterior predictive $P$-value ( $\mathrm{pp} P$-value) generated by calculating the proportion of the predicted values which are more extreme than the observed maximum, minimum and mean prevalence observed value. We calculated (i) the proportion of simulations of the data from the model for which the maximum prevalence across simulated barangays is greater than or equal to the maximum observed value, (ii) the proportion of simulations of the data from the model for which the minimum prevalence across simulated barangays is greater than or equal to the minimum observed value, and (iii) the proportion of simulations of the data from the model for which the mean prevalence across simulated barangays is greater than or equal to the mean observed value. If the model fits the data, the simulated values distribute closely around the observed values, 
thus, we expect a $\mathrm{pp} P$-value of around 0.5. Otherwise, for a biased model, the pp $P$-value will be close to 0 or 1 . Our aim was to test whether the model predicts a similar number of barangays with maximum and minimum prevalence values compared with the observed data. We generated $\mathrm{pp} P$-values for maximum, minimum and mean prevalence values for the models at five increasing SSA using 75,000 simulations. The second method used the area under the curve (AUC) of the receiving operating characteristics (ROC). We applied a threshold of $0.5 \%$ (prevalence mean in Mindanao region) since we are interested in knowing the ability of the models to discriminate the mean prevalence level in the study area. We also examined the ability of the model to discriminate the number of positive cases, thus, we used a threshold of 1 , which indicates the presence of at least one positive case. We used an AUC value of $70 \%$ to indicate acceptable predictive performance $[8,63]$.

\section{Software}

Model implementation was done in the software OpenBUGS 3.2.3 [64, 65] (Medical Research Council, Cambridge, UK and Imperial College London, UK). It was downloaded for free at [66]. We called OpenBUGS from $\mathrm{R}$ using the package R2OpenBUGS [67]. The spatial models were coded using the GeoBUGS [59] function as an add-on module to OpenBUGS. GeoBUGS provides an interface to work with conditional autoregressive and geo-statistical models. Data pre-processing and Ordinary Kriging was performed in R [68].

\section{Results \\ Modelling Schistosoma japonicum infection under the MAUP \\ Convolution model}

Our findings show that NDVI has a non-significant effect on the prevalence of $\mathrm{SCH}$ infection for all SSA, except for $\mathrm{SSA}=1 \mathrm{~km}$ (Additional file 3: Table S1, Fig. 3a). NDVI estimates vary gradually from 0.19 to 0.26 when increasing SSA until $500 \mathrm{~m}$. For $\mathrm{SSA}=1 \mathrm{~km}$, the estimate rapidly increases to 0.59 . Uncertainties are similar throughout all SSA (Fig. 4a, Table 2), slightly increasing when increasing SSA. The highest credible interval value is 0.60 for $\mathrm{SSA}=250 \mathrm{~m}$ and the lowest is 0.52 for $\mathrm{SSA}=30 \mathrm{~m}$.

NDWI has a significant negative effect on the prevalence of $\mathrm{SCH}$ infection throughout all SSAs (Additional file 3: Table S1, Fig. 3b). When SSA increases, parameter estimates increase from -1.06 to -0.76 , coming somewhat closer to zero. We found similar estimates for $\mathrm{SSA}=30 \mathrm{~m}, 90 \mathrm{~m}$ and $250 \mathrm{~m}$ (i.e. from -1.06 to -1.02 ), and for $\mathrm{SSA}=500 \mathrm{~m}$ and $1 \mathrm{~km}$ (i.e. from -0.8 to -0.76 ) (Fig. 4b). Uncertainty values are similar for all
SSAs and show a slight decrease when increasing SSA (Fig. 4b, Table 2). The highest uncertainty value equals 0.54 for $\mathrm{SSA}=30 \mathrm{~m}$, and the lowest value equals 0.44 for $\mathrm{SSA}=500 \mathrm{~m}$.

LSTD has a significant negative effect on the prevalence of $\mathrm{SCH}$ infection for almost all SSA, except for $\mathrm{SSA}=1 \mathrm{~km}$ (Additional file 3: Table S1, Fig. 3c). Similar parameter estimates equal to -0.71 are obtained for $\mathrm{SSA}=30 \mathrm{~m}, 90 \mathrm{~m}$ and $250 \mathrm{~m}$, while the parameter estimate increases slightly to -0.65 for $\mathrm{SSA}=500 \mathrm{~m}$. For $\mathrm{SSA}=1 \mathrm{~km}$, there is a noticeable increase in the parameter estimate to -0.01 (Figs. 3c, 4c). Uncertainty increases from 0.59 to 0.64 when increasing SSA from $30 \mathrm{~m}$ to $500 \mathrm{~m}$, but for SSA $=1 \mathrm{~km}$ there is a considerable increase in uncertainty to 1.49 (Fig. 4c).

LSTN has a significant negative effect on the prevalence of $\mathrm{SCH}$ infection for almost all SSA, except for $\mathrm{SSA}=1 \mathrm{~km}$ (Additional file 3: Table S1, Fig. 3d). Parameter estimates increase from -0.78 to -0.86 while increasing SSA from $30 \mathrm{~m}$ to $500 \mathrm{~m}$. For SSA $=1 \mathrm{~km}$, the parameter estimate rapidly goes up to 0.1 (Figs. 3d, 4d). Uncertainty increases slightly from 0.56 to 0.58 when increasing SSA from $30 \mathrm{~m}$ to $500 \mathrm{~m}$, but it increases considerably to 1.14 for $S S A=1 \mathrm{~km}$ (Table 2, Fig. 4d).

Elevation has a significant negative effect on the prevalence of $\mathrm{SCH}$ infection for all SSA, except for SSA $=1 \mathrm{~km}$ (Additional file 3: Table S1, Fig. 3e). When increasing SSA from $30 \mathrm{~m}$ to $500 \mathrm{~m}$, parameter estimates slightly decrease from -0.95 to -1.03 . For $S S A=1 \mathrm{~km}$, the parameter estimate considerably increases to -0.04 (Figs. 3e, 4e). Uncertainty values vary from 0.59 to 0.64 when increasing SSA from $30 \mathrm{~m}$ to $500 \mathrm{~m}$. For $\mathrm{SSA}=1 \mathrm{~km}$, uncertainty considerably decreases to 0.35 (Table 2, Fig. 4). The lowest uncertainty value is 0.35 for $\mathrm{SSA}=1 \mathrm{~km}$ and the highest is 0.66 for $\mathrm{SSA}=250 \mathrm{~m}$.

Finally, NDWB has a significant negative effect on the prevalence of SCH infection for all SSA (Additional file 3: Table S1, Fig. 3f). We found similar parameter estimates of $-0.28,-0.29$ and -0.31 for $\mathrm{SSA}=30 \mathrm{~m}, 90 \mathrm{~m}$ and $250 \mathrm{~m}$, respectively, and estimates of -0.38 and -0.4 for $\mathrm{SSA}=500 \mathrm{~m}$ and $1 \mathrm{~km}$, respectively (Fig. 3f). Uncertainties constantly increase from 0.32 to 0.39 (Table 2, Fig. 4f) when increasing SSA.

Intercept values range from -6.02 to -6.17 for almost all SSAs, except for $S S A=1 \mathrm{~km}$, where it is equal to -5.49 . The rate of decay of spatial autocorrelation $(\varphi)$ ranges from $1.65 \times 10^{-5}$ to $2.81 \times 10^{-4}$ for $S S A s=1 \mathrm{~km}$ and $500 \mathrm{~m}$, respectively.

Our findings show high and moderate correlation and determination $\left(R^{2}\right)$ coefficient values between the SSAs and all environmental covariates estimates (Table 3) with correlation coefficients ranging from -0.94 to 0.94 and $R^{2}$ values from 0.6 to 0.86 , respectively. Correlation 

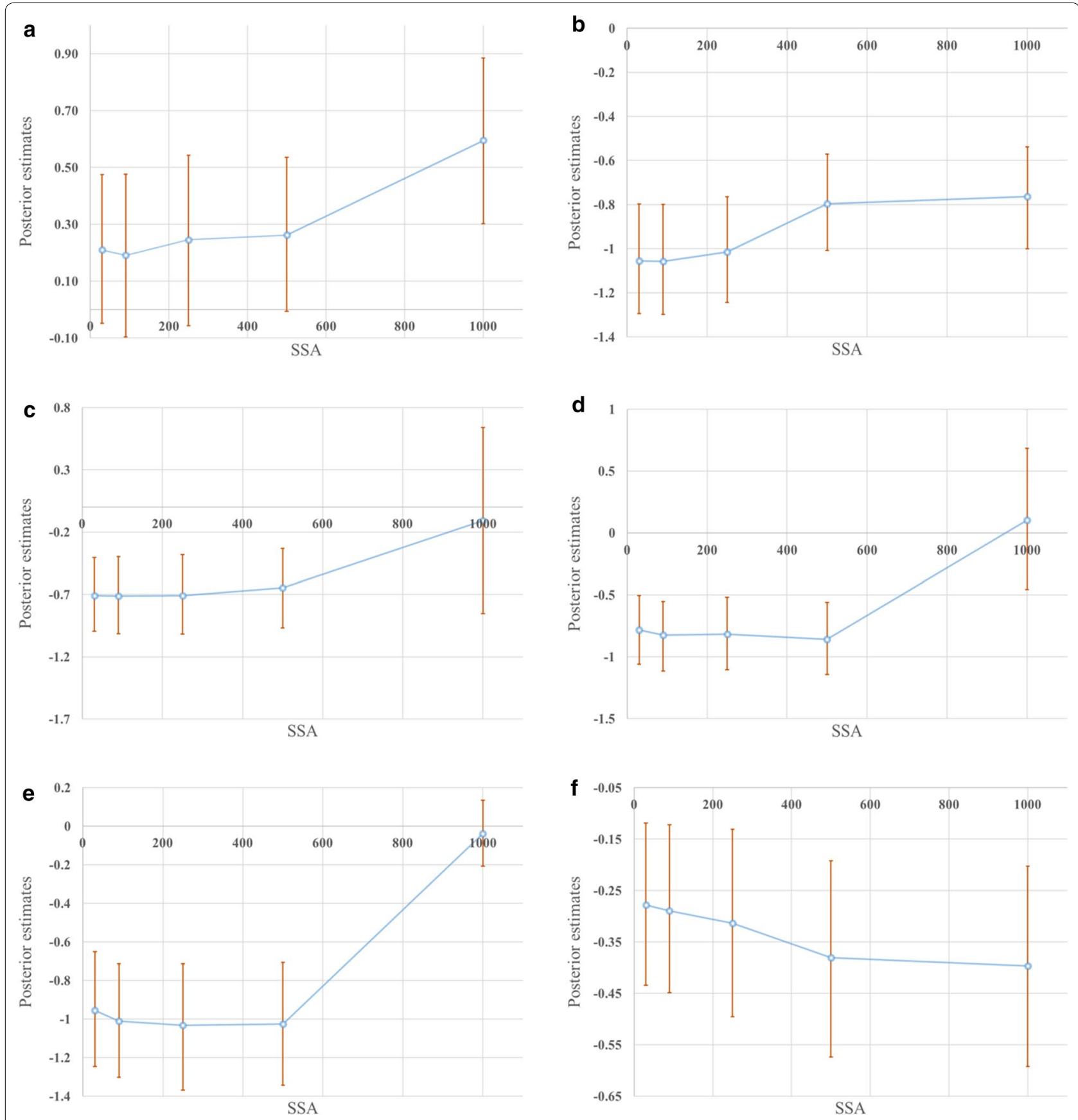

Fig. 3 Posterior estimates and their credible intervals. a Normalized difference vegetation index. b Normalized difference water index. c Land surface temperature day. $\mathbf{d}$ Land surface temperature night. e Elevation. $\mathbf{f}$ Nearest distance to water bodies. Abbreviation: SSA, spatial support of analysis

coefficients between the SSAs and uncertainties are high for LSTD, LSTN and NDWB with the values of 0.91 , 0.9 and 0.91 , respectively. Determination coefficients $R^{2}$ between the SSAs and uncertainties in the covariate estimates are moderate for LSTD, LSTN and NDWB with the values of $0.76,0.75$ and 0.76 , respectively (Table 3 ). Uncertainties in NDVI and NDWI estimates do not show any correlation with SSAs (Table 3). 

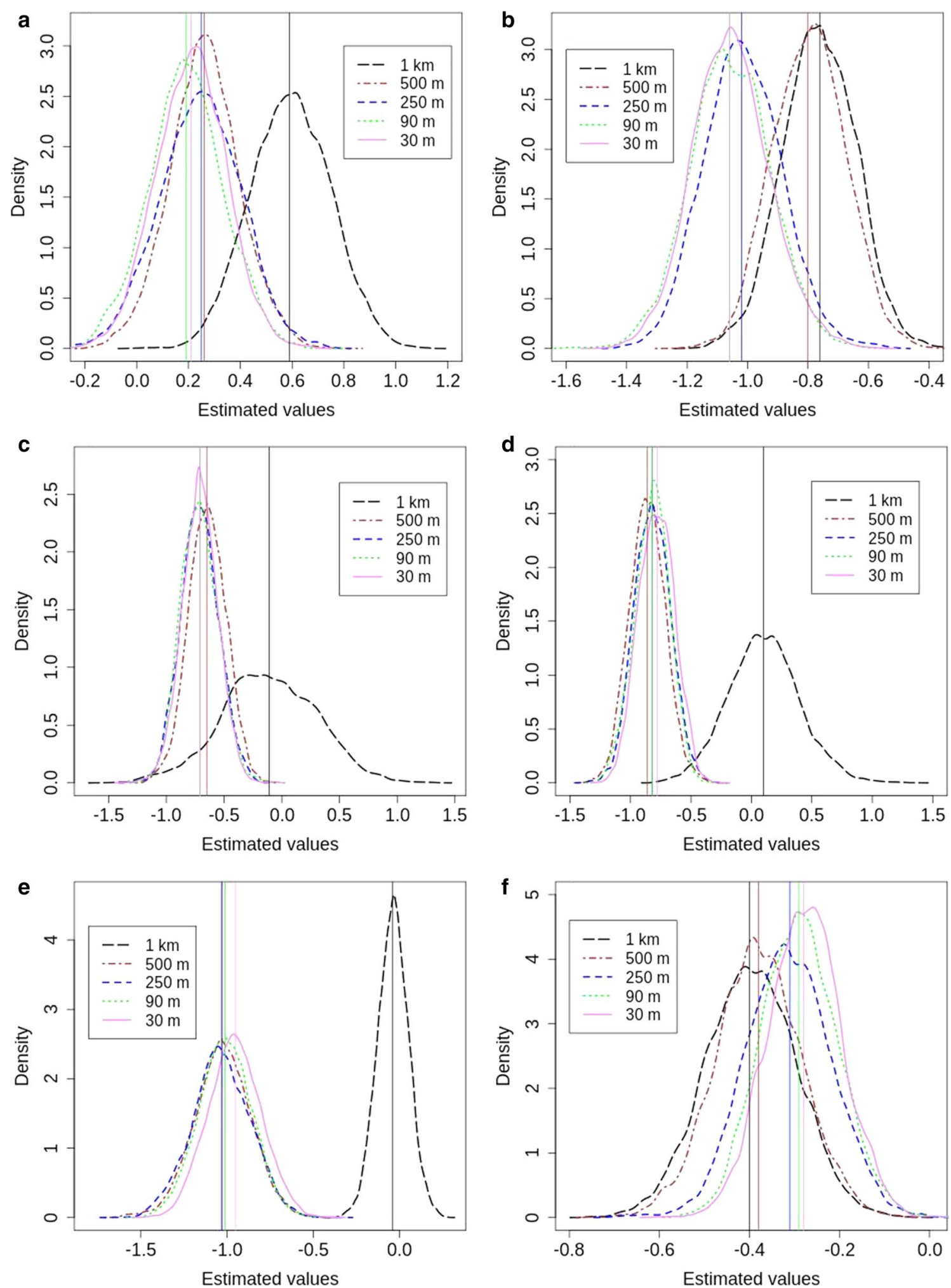

Fig. 4 Density plots for the risk factors regression coefficients. a Normalized difference vegetation index. b Normalized difference water index. $\mathbf{c}$ Land surface temperature day. $\mathbf{d}$ Land surface temperature night. e Elevation. $\mathbf{f}$ Nearest distance to water bodies 
Table 2 Credible interval widths (uncertainty) at five increasing spatial supports of analysis

\begin{tabular}{|c|c|c|c|c|c|c|}
\hline \multirow[t]{2}{*}{ Spatial supports of analysis } & \multicolumn{6}{|c|}{ Credible intervals width (uncertainty) } \\
\hline & NDVI & NDWI & LSTD & LSTN & $E$ & NDWB \\
\hline $30 \mathrm{~m}$ & 0.52 & 0.50 & 0.59 & 0.56 & 0.59 & 0.32 \\
\hline $90 \mathrm{~m}$ & 0.57 & 0.50 & 0.62 & 0.56 & 0.59 & 0.33 \\
\hline $250 \mathrm{~m}$ & 0.60 & 0.48 & 0.64 & 0.59 & 0.66 & 0.36 \\
\hline $500 \mathrm{~m}$ & 0.54 & 0.44 & 0.64 & 0.58 & 0.64 & 0.38 \\
\hline $1 \mathrm{~km}$ & 0.58 & 0.46 & 1.49 & 1.14 & 0.34 & 0.39 \\
\hline
\end{tabular}

Note: High uncertainty values are present in bold

Abbreviations: NDVI, normalized difference vegetation index; NDWI, normalized difference water index; LSTD, land surface temperature day; LSTN, land surface temperature night; NDWB, nearest distance to water bodies

Table 3 Correlation and determination coefficients between the spatial supports of analysis (SSAs) and environmental covariates estimates and uncertainties

\begin{tabular}{|c|c|c|c|c|c|c|}
\hline \multirow[t]{2}{*}{ Covariates } & \multicolumn{3}{|l|}{ Estimates } & \multicolumn{3}{|c|}{ Uncertainties } \\
\hline & $\begin{array}{l}\text { Correlation } \\
\text { coefficient }\end{array}$ & $\begin{array}{l}\text { Determination } \\
\text { coefficient }\left(R^{2}\right)\end{array}$ & $P$-value & $\begin{array}{l}\text { Correlation } \\
\text { coefficient }\end{array}$ & $\begin{array}{l}\text { Determination } \\
\text { coefficient }\left(R^{2}\right)\end{array}$ & $P$-value \\
\hline $\mathrm{NDVI}$ & 0.94 & 0.85 & 0.02 & 0.32 & -0.2 & 0.6 \\
\hline NDWI & 0.93 & 0.81 & 0.02 & -0.3 & -0.2 & 0.6 \\
\hline LSTD & 0.92 & 0.8 & 0.03 & 0.91 & 0.76 & 0.03 \\
\hline LSTN & 0.86 & 0.6 & 0.06 & 0.9 & 0.75 & 0.04 \\
\hline$E$ & 0.86 & 0.65 & 0.06 & -0.78 & 0.48 & 0.12 \\
\hline NDWB & -0.94 & 0.86 & 0.02 & 0.91 & 0.76 & 0.03 \\
\hline Variance & 0.64 & 0.21 & 0.25 & -0.54 & 0.06 & 0.35 \\
\hline
\end{tabular}

\section{Influence on predictions}

Differences between observed and predicted prevalence values are similar for the five SSA models (Fig. 5). Variation in these differences is highest between the 30 $\mathrm{m}$ and $1 \mathrm{~km}$ models $\left(R^{2}=0.94\right)$ and lowest between the $30 \mathrm{~m}$ and $90 \mathrm{~m}$ models $\left(R^{2}=0.99\right)$. Figure 5 shows that the maximum and minimum differences are $1.11 \%$ and $0.01 \%$, respectively, corresponding to the $1 \mathrm{~km} \mathrm{SSA}$ model. For fitted prevalence values higher than $2 \%$, all models underestimate the prevalence of infection, while for fitted prevalence values lower than $2 \%$, overestimation and underestimation occur for the five models (Fig. 5). A plot of the residuals against prevalence from Fig. 5 serve as a visual inspection of the fit, where we realize that it is based on positive predictive predictions.

Uncertainties on the predictions are similar for the five models (Additional file 4: Figure S1). Higher differences in uncertainty were found between the $500 \mathrm{~m}$ and $1 \mathrm{~km}$ models $\left(R^{2}=0.96\right)$, and lower differences were found between the $90 \mathrm{~m}$ and $250 \mathrm{~m}$ models $\left(R^{2}=0.99\right)$. The highest uncertainty value is $9.23 \%$ for all the models, except the $1-\mathrm{km}$ model with $8.9 \%$ and the lowest uncertainty value is $0.006 \%$ for the $1-\mathrm{km}$ model.

\section{Model validation}

The maximum and minimum observed prevalence values are $8.5 \%$ and $0.33 \%$, respectively. The first validation method shows $\mathrm{pp} P$-values for all SSA ranging from 0.64 to 0.67 for the first test statistic (Table 4). This means that simulated data slightly deviate from around 0.14 to 0.17 from the maximum observed prevalence value (Fig. 6). For all SSA it is likely to see a similar number of predicted maximum prevalence values compared to the observed data. For the second test statistic, $\mathrm{pp} P$-values ranged from 0.87 to 0.93 (Table 4). This means that simulated data are biased around 0.36 to 0.43 from the minimum observed prevalence data (Fig. 7). For almost all SSA, simulated data predict a higher number of minimum prevalence values compared to the observed data. For the last test statistics, $\mathrm{pp} P$-values ranged from 0.59 to 0.67 (Table 4), showing that simulated data deviate from around 0.09 to 0.17 from the mean observed prevalence value (Fig. 8).

Results from the second validation method show that all models have a high ability to predict prevalence values, with AUC values of 0.91 for $S S A=30 \mathrm{~m}, 90 \mathrm{~m}$, $250 \mathrm{~m}$ and $500 \mathrm{~m}$, and 0.93 for SSA $=1 \mathrm{~km}$. All models have a good ability to predict the positive number of 


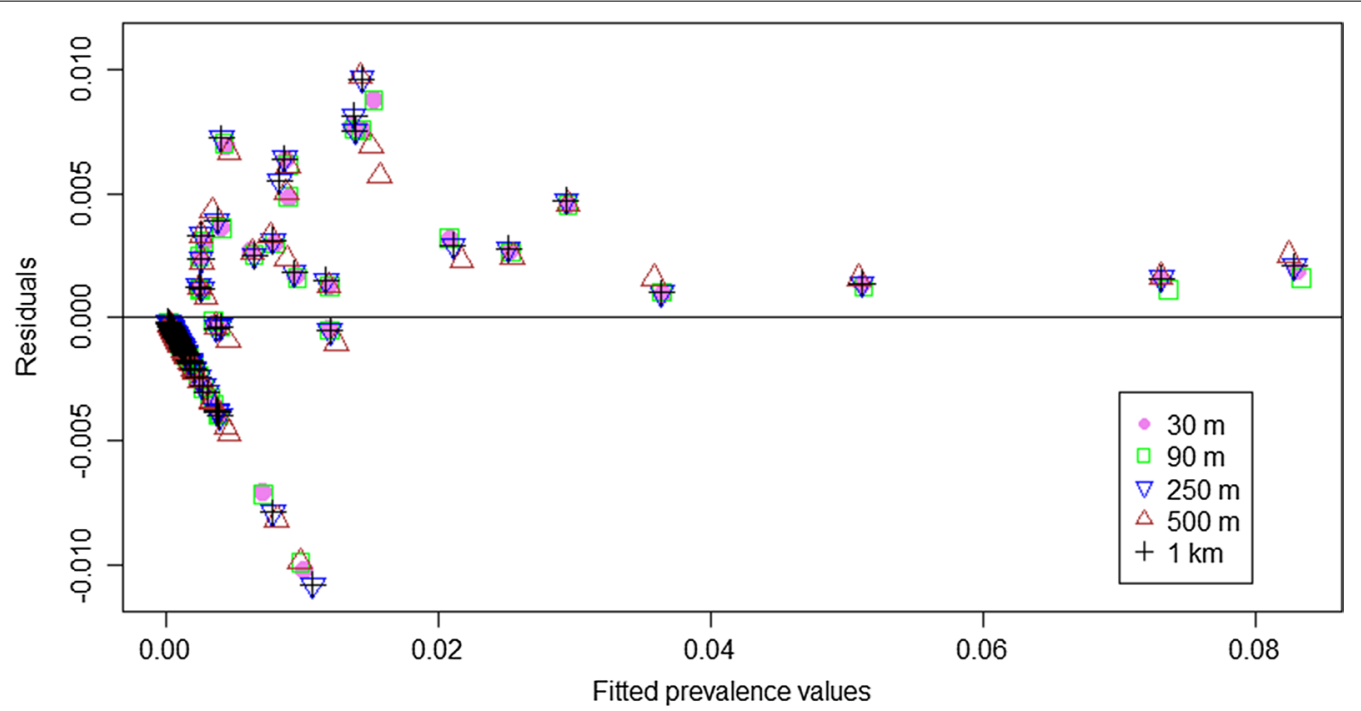

Fig. 5 Residual plot for the five increasing spatial supports of analysis. The x-axis represents the fitted prevalence values for the five spatial supports of analysis. The $y$-axis represents the residuals calculated by the difference between the observed and predicted prevalence values

Table 4 Resulting ppP-values for the test statistics: maximum (8.5\%), minimum $(0.33 \%)$ and mean $(0.5 \%)$ prevalence values at five increasing SSA

\begin{tabular}{llll}
\hline $\begin{array}{l}\text { Spatial supports of } \\
\text { analysis }\end{array}$ & $\begin{array}{l}\text { ppP-value } \\
\text { (maximum) }\end{array}$ & $\begin{array}{l}\text { ppP-value } \\
\text { (minimum) }\end{array}$ & $\begin{array}{l}\text { ppP- } \\
\text { value } \\
\text { (mean) }\end{array}$ \\
\hline $30 \mathrm{~m}$ & 0.66 & 0.87 & 0.66 \\
$90 \mathrm{~m}$ & 0.67 & 0.86 & 0.66 \\
$250 \mathrm{~m}$ & 0.66 & 0.88 & 0.63 \\
$500 \mathrm{~m}$ & 0.66 & 0.87 & 0.67 \\
$1 \mathrm{~km}$ & 0.64 & 0.93 & 0.59 \\
\hline
\end{tabular}

Abbreviation: $\mathrm{pp} P$-value: posterior predictive $P$-value

SCH cases. Models with SSA $=30 \mathrm{~m}, 90 \mathrm{~m}, 250 \mathrm{~m}$ and $500 \mathrm{~m}$ models have AUC values of 0.83 , while the $1 \mathrm{~km}$ SSA model presents a lower AUC value of 0.79, showing a decrease in the ability to predict the positive number of SCH cases.

\section{Discussion}

Schistosomiasis modelling studies have commonly used environmental risk factors as drivers for disease exposure and transmission $[69,70]$. The studies so far have used spatially misaligned environmental variables at different spatial supports of analysis, ignoring MAUP effects on the parameter estimates, predictions, and the relationship between disease morbidity indicators and risk factors. This study is the first effort to quantify the effects of modifying the areal unit (i.e. spatial support) of NDVI, NDWI, LSTD, LSTN, E and NDWB, on model parameter estimates and their uncertainties. Uncertainty may be quantified using measures of accuracy or imprecision [15]. We evaluated uncertainty using measures of imprecision based on the nature of the disease and the survey data available and quantified it using credible intervals in a Bayesian setting. We applied it to S. japonicum infection modelling in the Mindanao region, the Philippines.

Our findings show that the environmental risk factors NDVI, NDWI, LSTD, LSTN and E behave similarly when increasing the SSA from $30 \mathrm{~m}$ to $1 \mathrm{~km}$ (Table 3). An increase in SSA from $30 \mathrm{~m}$ to $500 \mathrm{~m}$ does not represent any significant changes in parameter estimates. Conversely, for $\mathrm{SSA}=1 \mathrm{~km}$, all show a considerable increase in their estimates. The reasons are explained below.

NDVI has a positive effect on $\mathrm{SCH}$, meaning that higher NDVI values increase the prevalence of infection. This is explained by the positive relationship between vegetation, moisture and snail density [37]. NDVI effects are not significant for SSA $<1 \mathrm{~km}$, because NDVI is an indicator of greenness that is mainly effective for arid areas and Mindanao is not arid. However, the NDVI effect becomes significant on the prevalence of $\mathrm{SCH}$ infection for $\mathrm{SSA}=1 \mathrm{~km}$. This could be because NDVI effects on $\mathrm{SCH}$ prevalence are greater at global scales [8] than at local scales. This might be explained by the fact that prevalence values al local scales can vary significantly at nearby locations, as it depends not only on the nature of the parasite life-cycle, which requires optimal habitat conditions (i.e. environmental conditions), but also on sanitation conditions on the area 


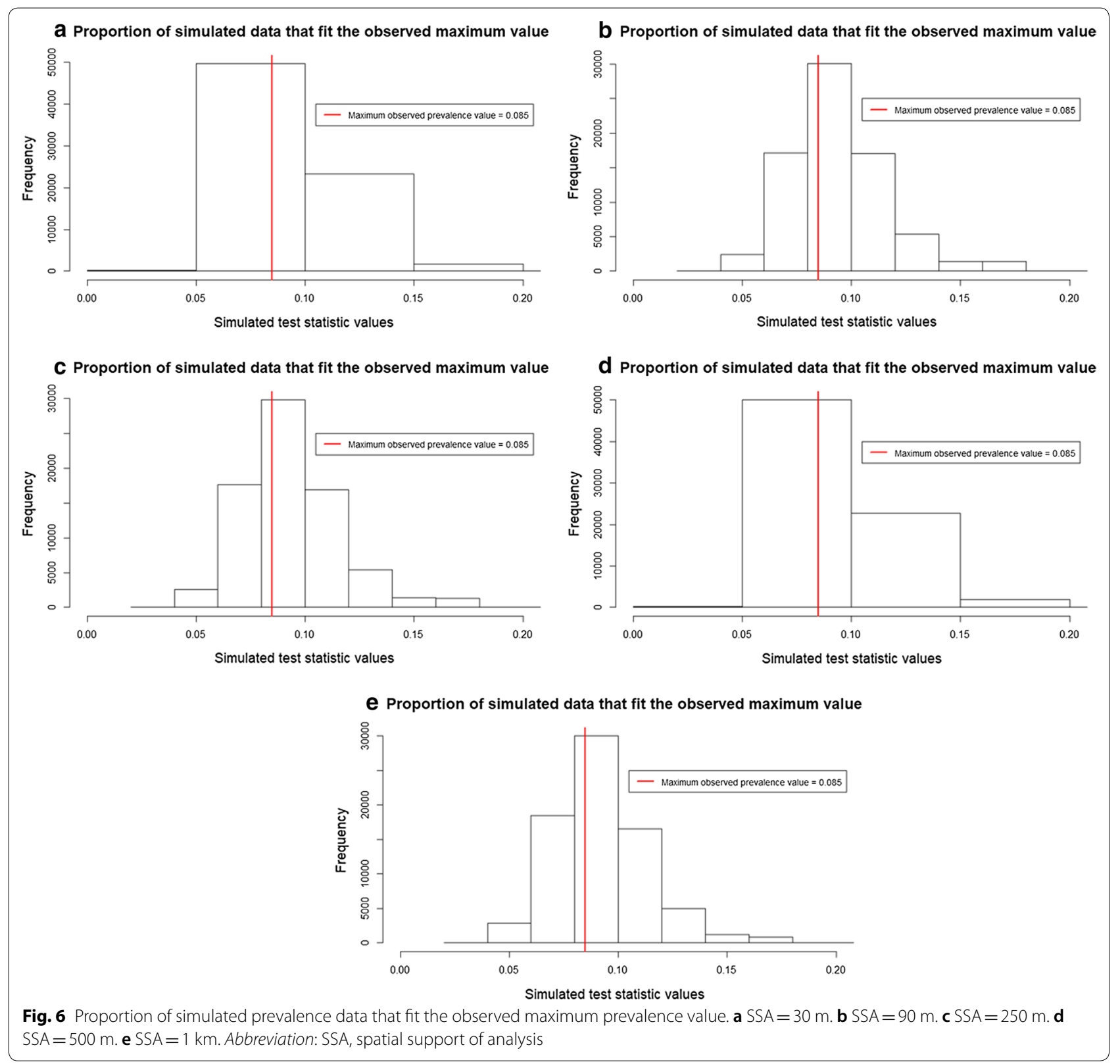

[71]. The increase in uncertainty values with increasing SSA is due to the coarse areal pixels $\geq 250$ m resolution that does not reliably represent rice paddy fields. Those are substantially smaller than 25 ha, i.e. are covered by at most four pixels [72].

For SSA $=30 \mathrm{~m}, 90 \mathrm{~m}, 250 \mathrm{~m}$ and $500 \mathrm{~m}$, LSTD, LSTN and $\mathrm{E}$ have a significant negative effect on $\mathrm{SCH}$ prevalence. Conversely for $\mathrm{SSA}=1 \mathrm{~km}$, their parameter estimates are close to zero. This means that when the areal unit reaches $1 \mathrm{~km}$, the effect of these covariates on the prevalence of $\mathrm{SCH}$ infection becomes non-significant. This is also observed from the credible intervals of these covariates for the $1-\mathrm{km}$ SSA model. The reason is that the homogeneity of the covariate values increases when increasing the SSA. LST is a proxy of the ambient temperature of the air, which reflects the thermal conditions of shallow waters [27]. Its negative relationship with the prevalence of infection could be explained by the fact that temperatures above $19-20^{\circ} \mathrm{C}$ do not influence the release of cercariae from the infected host to the infection foci [73], as well as temperatures below approximately $15{ }^{\circ} \mathrm{C}$ arrest the development of S. japonicum in the snail host [74]. The minimum LST value at night is around $21^{\circ} \mathrm{C}$, while the maximum LST value during the day is $31{ }^{\circ} \mathrm{C}$. LSTD and LSTN uncertainty values for $S S A=1 \mathrm{~km}$ are remarkably high as compared to other SSA. This is 


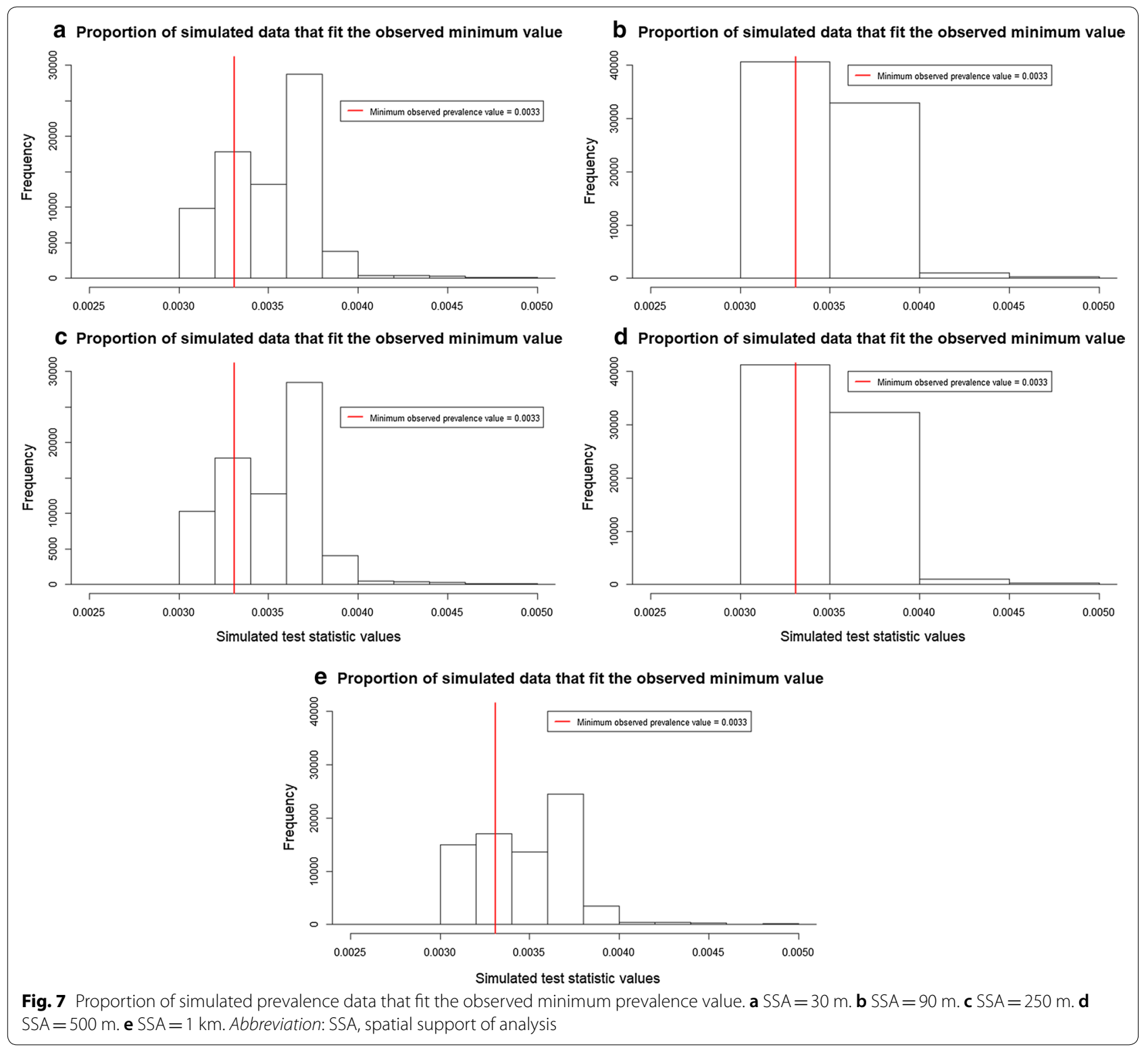

explained by the coarse LSTD and LSTN areal pixels of $1 \mathrm{~km}^{2}$ that cannot reliably represent low and high temperature zones in city areas that range from 0.02 to $3 \mathrm{~km}^{2}$ [27]. Elevation has a negative effect on $\mathrm{SCH}$. This was expected as in areas with high elevation values $(>2300 \mathrm{~m})$ the risk of infection is low [75]. Conversely, the risk of infection is high for elevation areas below $900 \mathrm{~m}$. Elevation uncertainty values are similar for all SSA, except for $\mathrm{SSA}=1 \mathrm{~km}$, where its value considerably decreases to 0.34 . Here we see the effect of the gradual changes of elevation in Mindanao region are gradual and without steep slopes [27]. Using data directly at the $1-\mathrm{km}$ SSA could give reliable elevation values, but with a non-significant effect on the disease prevalence.
For NDWB and NDWI, an increase in SSA from $30 \mathrm{~m}$ to $250 \mathrm{~m}$ represents non-significant changes in parameter estimates, which range from -1.06 to -1.02 for NDWI, and from -0.31 to -0.28 for NDWB. Conversely, when increasing the SSA to $500 \mathrm{~m}$, parameter estimates change to -0.8 and -0.38 for NDWI and NDWB, respectively. For $\mathrm{SSA}=500 \mathrm{~m}$ and $1 \mathrm{~km}$, NDWI estimates increase, having a less significant effect on $\mathrm{SCH}$ prevalence, again due to the increase in the homogeneity of the covariate values when increasing SSA. Higher NDWI values show the presence of potential hidden infection foci. Nevertheless, results show that NDWI presents a negative effect on SCH (Additional file 3: Table S1). This could be because NDWI cannot efficiently suppress the signal 


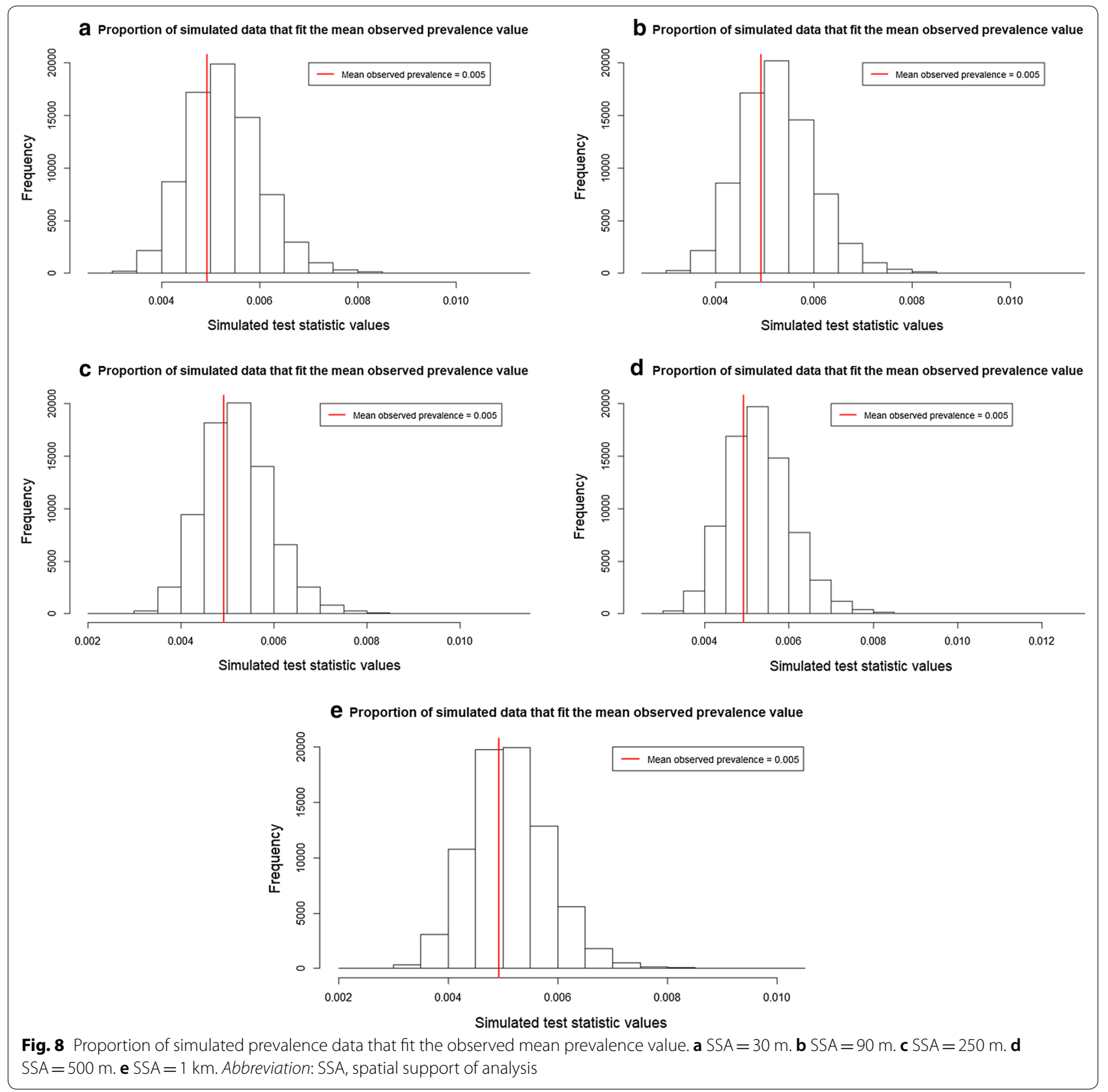

from build-up land mixing enhanced water features with build-up land noise. Thus, build-up noise could also have high NDWI values [40]. According to Gu et al. [76] NDWI values lower than 0.3 indicate the presence of drought areas. In our study area, we found that around $77 \%$ of Mindanao present drought conditions, explaining the negative effect on the disease. NDWB estimates decrease when increasing SSAs (Table 3), specially for $\mathrm{SSA}=500 \mathrm{~m}$ and $1 \mathrm{~km}$, but their significance on $\mathrm{SCH}$ prevalence increases. A possible explanation is that people that move larger distances to water bodies are most likely to get infected. This could be because at spatial supports $<1 \mathrm{~km}$, NDWB values seem to be more homogenous than at smaller spatial supports, showing a weaker relationship with the disease (Additional file 3: Table S1). For spatial supports $>1 \mathrm{~km}$, neighbouring pixels present more heterogeneous values, which could be because of the aggregation process, but also because of the use of some kind of transportation media that allows apparent reduction of travel distances in a relatively large area $\left(1 \mathrm{~km}^{2}\right)$. Clearly, transportation (type of road and media of transportation) plays an important role [77].

Uncertainty values for NDWI decrease when increasing the SSA, with a minimum of 0.44 for SSA $=500 \mathrm{~m}$. 
Clearly, NDWI data originally available at SSA $=250 \mathrm{~m}$ are more reliable than values modified to larger SSAs. Using ordinary kriging for interpolation increases the variance in the estimates in a somewhat unrealistic way since it uses a constant mean [58], while in reality, means are different. Uncertainty values of NDWB, for instance, increase with increasing SSA due to the coarse areal pixel units $\geq 0.25 \mathrm{~km}^{2}$. Such a size is insufficient to reliable define nearest distances to water bodies in city areas of 0.02 to $3 \mathrm{~km}^{2}$.

Our aim was not to compare the performance of the models as we used the same model structure, number and type of covariates in the five models. Thus the model itself is practically the same for all SSA. Although our aim was not focused on model comparison, the resulting DIC values from Additional file 3: Table S1 suggest the use of spatial support sizes below or equal to $250 \mathrm{~m}$ in $\mathrm{SCH}$ modelling. This is shown by the low DIC values from 86.67 to 140.5 for SSA $\leq 250 \mathrm{~m}$ and high DIC values of 143.7 and 147.5 for the $500 \mathrm{~m}$ and $1 \mathrm{~km}$ models, respectively (Additional file 3: Table $\mathrm{S} 1$ ).

When modelling prevalence of $S$. japonicum infection in Mindanao, the effect of increasing SSA, or modifying the areal unit of analysis, from $30 \mathrm{~m}$ to $500 \mathrm{~m}$, produces a gradual and continuous increase on the parameter estimates and their associated uncertainties. For $S S A=1 \mathrm{~km}$, sudden changes occur in the relationship between the risk factors and the prevalence of the disease. This is shown by the non-significant effect of almost all explanatory variables on S. japonicum prevalence. Results suggest that the use of environmental data extracted at $\mathrm{SSA}=1 \mathrm{~km}$ is not appropriate for the modelling of $S$. japonicum prevalence.

A Bayesian statistical method was used to model the disease along with a convolution regression model, which corrected for pure specification bias on our estimates. This is a relevant contribution to the analysis of uncertainties in this type of spatial epidemiological study. For future studies, new trends in geospatial artificial intelligence (geoAI), that could resolve limitations regarding the MAUP for exposure modelling studies, are emerging to model schistosomiasis [78] as well as other diseases [79]. We particularly identified (i) the use of high-performance computing to handle spatiotemporal big data, and (ii) machine and deep learning algorithms implementation to big data infrastructures to extract relevant disease or environmental information [79, 80]. One example is a data-driven method used to predict particulate matter air pollution $\left(\mathrm{PM}_{2.5)}\right.$ in Los Angeles, CA, USA. Here, machine learning was used on spatial big data, i.e. land use and roads, derived from OpenStreeMap, to predict $\mathrm{PM}_{2.5}$ concentrations. When generating relative importance measures for the different risk factors, MAUP effects reduced when applying a random forest model that was trained with the distances between the features and the monitoring $\mathrm{PM}_{2.5}$ stations, [81]. The rapid development of geoAI methods, their advantage to deal with big data, and their rapid computational time, makes them an attractive and advantageous tool to tackle limitations with modelling schistosomiasis and other diseases. There is still little work done in this field, but we think it is valuable to further explore geoAI solutions to deal with the MAUP, and perhaps other inherent uncertainties produced in disease modelling and mapping.

Finding MAUP effects on the various environmental risk factors used for modelling $S$. japonicum prevalence, is a step forward to the uncertainty analysis in the schistosomiasis, and possibly other diseases. The present research deals with limitations such as the use of aggregated disease data, due to the lack of geolocated individual-level surveys. It also provides a robust method for the selection of an appropriate spatial data structure, which at the same time, enables the acquisition of more reliable parameter estimates, and defines a clear relationship between the risk factors and the disease. From the public health perspective, this research can support helminth control programmes by providing less uncertain models and maps. Epidemiologists and health scientists could use these maps to identify risk areas for the control and prevention of the disease [12, 82], which in the case of schistosomiasis, is generally based on mass drug administration campaigns addressed to the identified at-risk populations. The provision of reliable information is relevant to guide mass drug administration campaigns by enhancing the assessment of the infection risk, understanding its potential impacts on human health $[15,83]$ and avoiding erroneous conclusions and decisions about the spatial distribution of schistosomiasis [15, 27]. This research is also relevant to evaluate the effectiveness of mass drug administration campaigns, as it could guide the identification of persistent hot spots, or places where prevalence of infection remains despite mass drug administration efforts [71]. It is known that despite the implementation of mass drug administration campaigns, some places do not show a decrease in local SCH transmission. This is because these campaigns do not only depend on the nature of the parasite life-cycle and the poor sanitation conditions, but also on the local environmental factors, drivers for $\mathrm{SCH}$ transmission. Finding relevant environmental factors at local level would allow more intensive efforts at persistent hot spots.

\section{Conclusions}

The present study shows a clear MAUP effect on $S$. japonicum modelling. An increase in parameter estimates and their associated uncertainties occurs when 
increasing the spatial support of analysis (SSA). It also showed that using environmental data extracted at $\mathrm{SSA}=1 \mathrm{~km}$ is not relevant for S. japonicum prevalence of infection at this specific extent of analysis, as this leads to wrong conclusions about the distribution of the disease and its relationship with the potential risk factors. Thus, the use of maps based upon this information is to be avoided as these may guide health scientists in the control or prevention of the disease astray. The results from this study could guide other disease modelling studies as they suggest a spatial support sizes at which environmental information has no longer a significant effect on the disease, and which data structure is recommended for the modelling. Epidemiologists, decision makers and health scientists could thus benefit from those, e.g. to better understand and quantify MAUP effects on the relationship between the disease and its risk factors, and to provide reliable maps that are useful for disease control and prevention.

\section{Supplementary information}

Supplementary information accompanies this paper at https://doi. org/10.1186/s13071-020-3987-5.

Additional file 1: Table S1. Survey data aggregated at the barangay level. These data show the number of positive cases (y) and the total number of sampled people $(n)$ in a barangay (k).

Additional file 2: Text S1. Code for the convolution model used in OpenBUGS. It includes the prior distributions used for the covariate and spatial parameters and the model itself. The model uses two indexes, $k$ for the barangay and $j$ for the number of city pixels within barangays. The betas are the individual-level regression coefficients, $m$ is the number of city pixels in a barangay. Covariates are $n d v i$ : normalized difference vegetation index, ndwi: normalized difference water index, Istd: land surface temperature day, Istn: land surface temperature night, e: elevation, ndwb: nearest distance to water bodies. The spatial parameter is represented as $s$.

Additional file 3: Table S2. Regression coefficient estimates, variance of spatial random effect, correlation decay coefficient and deviance information criteria for each risk factor at five descending spatial supports of analysis.

Additional file 4: Figure S1. Residual plot for the five increasing spatial supports of analysis. a SSA $=30 \mathrm{~m}$. b SSA $=90 \mathrm{~m}$. c SSA $=250 \mathrm{~m}$. d $S S A=500 \mathrm{~m}$. e $S S A=1 \mathrm{~km}$. The $x$-axis represents the fitted prevalence values for the five spatial supports of analysis. The $y$-axis represents the residuals calculated by the difference between the observed and predicted prevalence values.

\section{Abbreviations}

ASTER: advanced spaceborne thermal emission and reflection radiometer; AUC: area under the curve; BUGS: Bayesian inference using Gibbs sampling; E: elevation; EO: Earth Observation; geoAl: geospatial artificial intelligence; GDEM: global digital elevation map; GIS: geographical information systems; LSTD: land surface temperature day; LSTN: land surface temperature night; MAUP: modifiable areal unit problem; MCMC: Markov chain Monte Carlo; MODIS: moderate resolution imaging spectroradiometer; NDVI: normalized difference vegetation index; NDWB: nearest distance to water bodies; NDWI: normalized difference water index; ROC: receiver operator characteristic; $\mathrm{SCH}$ schistosomiasis; SSA: spatial support of analysis; USGS: United States Geological Survey.
Acknowledgments

Not applicable.

\section{Authors' contributions}

ALAN, FO and RJSM conceptualized the study. ALAN carried out formal analysis and investigation. ALAN and FO designed the methods. LRL and RJSM provided the resources. ALAN performed the programming in $\mathrm{R}$ and Open BUGS Software. FO, RJSM and AS supervised the research. ALAN performed the validation, visualization and writing of the original draft. ALAN, FO, RJSM and AS wrote, reviewed and edited the final document. All authors read and approved the final manuscript.

\section{Funding}

The research team acknowledges the World Health Organization funds provided to conduct the surveys. This research received no external funding. ALAN's doctoral research is funded by the University of Twente. The funders had no role in study design, data collection and analysis, decision to publish, or preparation of the manuscript.

\section{Availability of data and materials}

Data supporting the conclusions of this article are included within the article and its additional files. The datasets used and/or analysed during the present study are available from the corresponding author upon reasonable request.

\section{Ethics approval and consent to participate}

The data used in this study were collected in 2005 when there was no requirement for ethical review and clearance. This study used aggregated survey data at the barangay level, which enabled the full de-identification of individuals involved in the survey.The study results represent part of the Ph.D. thesis entitled "Statistical evaluation of spatial uncertainty in schistosomiasis mapping", which was published as: Araujo Navas AL. Statistical evaluation of spatial uncertainty in schistosomiasis mapping. Enschede: University of Twente, Faculty of Geo-Information Science and Earth Observation (ITC), 2019. 157 p. (ITC Dissertation). https://doi.org/10.3990/1.9789036548281.

\section{Consent for publication}

Not applicable.

\section{Competing interests}

The authors declare that they have no competing interests.

\section{Author details}

${ }^{1}$ Faculty of Geo-information Science and Earth Observation (ITC), University of Twente, PO Box 217, 7500 AE Enschede, The Netherlands. ${ }^{2}$ UQ Spatial Epidemiology Laboratory, School of Veterinary Science, The University of Queensland, Gatton, QLD 4343, Australia. ${ }^{3}$ Child Health and Environment Program, Child Health Research Centre, The University of Queensland, South Brisbane, QLD 4101, Australia. ${ }^{4}$ Department of Parasitology, College of Public Health, University of the Philippines Manila, 1000 Manila, Philippines.

Received: 11 January 2020 Accepted: 21 February 2020

Published online: 02 March 2020

\section{References}

1. Walz Y, Wegmann M, Dech S, Vounatsou P, Poda J-N, N'Goran EK, et al. Modeling and validation of environmental suitability for schistosomiasis transmission using remote sensing. PLoS Negl Trop Dis. 2015;9:e0004217.

2. Leenstra T, Acosta LP, Langdon GC, Manalo DL, Su L, Olveda RM, et al. Schistosoma japonicum, anemia, and iron status in children, adolescents, and young adults in Leyte, Philippines. Am J Clin Nutr. 2006;83:371-9.

3. Coutinho HM, McGarvey ST, Acosta LP, Manalo DL, Langdon GC, Leenstra T, et al. Nutritional status and serum cytokine profiles in children, adolescents, and young adults with Schistosoma japonicum-associated hepatic fibrosis, in Leyte, Philippines. J Infect Dis. 2005;192:528-36.

4. Jia TW, Zhou XN, Wang XH, Utzinger J, Steinmann P, Wu XH. Assessment of the age-specific disability weight of chronic Schistosomia japonicum. Bull World Health Organ. 2007;85:458-65. 
5. Tarafder MR, Balolong E, Carabin H, Belisle P, Tallo V, Joseph L, et al. A cross-sectional study of the prevalence of intensity of infection with Schistosoma japonicum in 50 irrigated and rain-fed villages in Samar province, the Philippines. BMC Public Health. 2006;6:61

6. Yang K, Wang XH, Yang GJ, Wu XH, Qi YL, Li HJ, et al. An integrated approach to identify distribution of Oncomelania hupensis, the intermediate host of Schistosoma japonicum, in a mountainous region in China. Int J Parasitol. 2008;38:1007-16.

7. Hotez PJ, Alvarado M, Basanez MG, Bolliger I, Bourne R, Boussinesq $M$, et al. The global burden of disease study 2010: interpretation and implications for the neglected tropical diseases. PLoS Negl Trop Dis. 2014;8:e2865.

8. Soares Magalhães RJ, Salamat MS, Leonardo L, Gray DJ, Carabin H, Halton K, et al. Geographical distribution of human Schistosoma japonicum infection in The Philippines: tools to support disease control and further elimination. Int J Parasitol. 2014:44:977-84.

9. Herbreteau V, Salem G, Souris M, Hugot JP, Gonzalez JP. Thirty years of use and improvement of remote sensing, applied to epidemiology: from early promises to lasting frustration. Health Place. 2007;13:400-3.

10. Kalluri S, Gilruth P, Rogers D, Szczur M. Surveillance of arthropod vectorborne infectious diseases using remote sensing techniques: a review. PLoS Pathogens. 2007;3:e116.

11. Zhang ZJ, Manjourides J, Cohen T, Hu Y, Jiang QW. Spatial measurement errors in the field of spatial epidemiology. Int J Health Geogr. 2016;15:12.

12. Soares Magalhães RJ, Clements ACA, Patil AP, Gething PW, Brooker S. The applications of model-based geostatistics in helminth epidemiology and control. Adv Parasitol. 2011;74:267-96.

13. Cadavid Restrepo AM, Yang YR, McManus DP, Gray DJ, Giraudoux P, Barnes TS, et al. The landscape epidemiology of echinococcoses. Infect Dis Poverty. 2016;5:13.

14. Weiss DJ, Mappin B, Dalrymple U, Bhatt S, Cameron E, Hay SI, et al. Reexamining environmental correlates of Plasmodium falciparum malaria endemicity: a data-intensive variable selection approach. Malar J. 2015;14:68.

15. Araujo Navas AL, Hamm NAS, Soares Magalhães RJ, Stein A. Mapping soil transmitted helminths and schistosomiasis under uncertainty: a systematic review and critical appraisal of evidence. PLoS Negl Trop Dis. 2016;10:e0005208.

16. Wang XH, Zhou XN, Vounatsou P, Chen Z, Utzinger J, Yang K, et al. Bayesian spatio-temporal modeling of Schistosoma japonicum prevalence data in the absence of a diagnostic 'gold' standard. PLoS Negl Trop Dis. 2008:2:e250.

17. Walz Y, Wegmann M, Leutner B, Dech S, Vounatsou P, N'Goran EK, et al. Use of an ecologically relevant modelling approach to improve remote sensing-based schistosomiasis risk profiling. Geospat Health. 2015:10:271-9.

18. Young LJ, Gotway CA, Yang J, Kearney G, DuClos C. Assessing the association between environmental impacts and health outcomes: a case study from Florida. Stat Med. 2008;27:3998-4015.

19. Simoonga C, Utzinger J, Brooker S, Vounatsou P, Appleton CC, Stensgaard AS, et al. Remote sensing, geographical information system and spatial analysis for schistosomiasis epidemiology and ecology in Africa. Parasitology. 2009;136:1683-93.

20. Atkinson PM, Graham AJ. Issues of scale and uncertainty in the global remote sensing of disease. In: Hay SI, Graham A, Rogers DJ, editors. Global mapping of infectious diseases: methods, examples and emerging applications. San Diego: Elsevier Academic Press Inc.; 2006. p. 79-118.

21. Schur N, Hurlimann E, Garba A, Traore MS, Ndir O, Ratard RC, et al. Geostatistical model-based estimates of schistosomiasis prevalence among individuals aged $\leq 20$ years in West Africa. PLoS Negl Trop Dis. 2011;5:e1194.

22. Schur N, Hurlimann E, Stensgaard AS, Chimfwembe K, Mushinge G, Simoonga C, et al. Spatially explicit Schistosoma infection risk in eastern Africa using Bayesian geostatistical modelling. Acta Trop. 2013:128:365-77.

23. Dungan JL, Perry JN, Dale MRT, Legendre P, Citron-Pousty S, Fortin MJ, et al. A balanced view of scale in spatial statistical analysis. Ecography. 2002;25:626-40

24. Openshaw S. The modifiable areal unit problem. Norwich: GeoBooks; 1984
25. Hellsten AS. A spatio-temporal ammonia emissions inventory for the UK. 2006. https://www.era.lib.ed.ac.uk/handle/1842/24693. Accessed 26 Apr 2018

26. Schur N, Vounatsou P, Utzinger J. Determining treatment needs at different spatial scales using geostatistical model-based risk estimates of schistosomiasis. PLoS Negl Trop Dis. 2012;6:e1773.

27. Araujo Navas AL, Osei F, Leonardo LR, Soares Magalhães RJ, Stein A. Modeling Schistosoma japonicum infection under pure specification bias: impact of environmental drivers of infection. Int J Environ Res Public Health. 2019;16:176

28. Leonardo L, Rivera P, Saniel O, Solon JA, Chigusa Y, Villacorte E, et al. New endemic foci of schistosomiasis infections in the Philippines. Acta Trop. 2015;141:354-60.

29. Leonardo L, Acosta LP, Olveda RM, Aligui GDL. Difficulties and strategies in the control of schistosomiasis in the Philippines. Acta Trop. 2002;82:295-9.

30. Zhou XN, Bergquist R, Leonardo L, Yang GJ, Yang K, Sudomo M, et al. Schistosoma japonicum: control and research needs. Adv Parasitol. 2010;72:145-78.

31. Leonardo L, Rivera P, Saniel O, Villacorte E, Lebanan MA, Crisostomo B, et al. A national baseline prevalence survey of schistosomiasis in the Philippines using stratified two-step systematic cluster sampling design. J Trop Med. 2012;2012:8

32. Leonardo LR, Rivera P, Saniel O, Villacorte E, Crisostomo B, Hernandez L, et al. Prevalence survey of schistosomiasis in Mindanao and the Visayas, The Philippines. Parasitol Int. 2008;57:246-51.

33. DIVA-GIS free, simple and effective. Hijmans R, Rojas E, Cruz M, O'Brien R, Barrantes I. University of California and International Potato Center in Peru 2018. 2011. http://www.diva-gis.org/Data. Accessed 8 Apr 2018.

34. Santos FLN, Cerqueira EJL, Soares NM. Comparison of the thick smear and Kato-Katz techniques for diagnosis of intestinal helminth infections. Rev Soc Bras Med Trop. 2005;38:196-8.

35. Brooker S, Hay S, Issae W, Hall A, Kihamia C, Lawambo N, et al. Predicting the distribution of urinary schistosomiasis in Tanzania using satellite sensor data. Trop Med Int Health. 2001;6:998-1007.

36. Brooker S, Hay SI, Tchuente LAT, Ratard R. Using NOAA-AVHRR data to model human helminth distributions in planning disease control in Cameroon, West Africa. Photogramm Eng Remote Sens. 2002;68:175-9.

37. Walz Y, Wegmann M, Dech S, Raso G, Utzinger J. Risk profiling of schistosomiasis using remote sensing: approaches, challenges and outlook. Parasites Vectors. 2015;8:16.

38. Malone JB, Yilma JM, MCCarroll JC, Erko B, Mukaratirwa S, Zhou XY. Satellite climatology and the environmental risk of Schistosoma mansoni in Ethiopia and east Africa. Acta Trop. 2001;79:59-72.

39. Zhou YB, Liang S, Jiang QW. Factors impacting on progress towards elimination of transmission of Schistosoma japonicum in China. Parasites Vectors. 2012;5:7

40. $\mathrm{Xu} \mathrm{H}$. Modification of normalised difference water index (NDWI) to enhance open water features in remotely sensed imagery. Int J Remote Sens. 2006;27:3025-33.

41. Woolhouse M, Chandiwana S. Population dynamics model for Bulinus globosus, intermediate host for Schistosoma haematobium, in river habitats. Acta Trop. 1990;47:151-60.

42. Pietrock M, Marcogliese DJ. Free-living endohelminth stages: at the mercy of environmental conditions. Trends Parasitol. 2003;19:293-9.

43. Stensgaard AS, Jorgensen A, Kabatereine NB, Rahbek C, Kristensen TK. Modeling freshwater snail habitat suitability and areas of potential snailborne disease transmission in Uganda. Geospat Health. 2006;1:93-104.

44. Stensgaard AS, Utzinger J, Vounatsou P, Hurlimann E, Schur N, Saarnak CFL, et al. Large-scale determinants of intestinal schistosomiasis and intermediate host snail distribution across Africa: does climate matter? Acta Trop. 2013:128:378-90.

45. ESRI. ArcGIS desktop. New release simplifies your work, provides new ways to share information, supplies GIS in the cloud. 10th ed. Redlands: Environmental Systems Research Institute; 2011.

46. Planet OSM. Open Street Map Project. 2017. https://planet.osm.org. Accessed 21 Nov 2017

47. Humanitarian data exchange v1.25.3. United Nations office for the coordination of humanitarian affairs, New York and Geneva. 2018. https://data. humdata.org/search?groups=phl\&q=\&ext_page_size=25. Accessed 10 Apr 2018. 
48. Global Data Explorer. U.S. Department of Interior. 2017. https://gdex. cr.usgs.gov/gdex/. Accessed 7 Aug 2017.

49. King G. A solution to the ecological inference problem: reconstructing individual behavior from aggregate data. 1st ed. Princeton: Princeton University Press; 1997.

50. Wakefield J, Lyons H. Spatial aggregation and the ecological fallacy. Handb Mod Stat Methods. 2010;2010:541-58.

51. Gelfand AE, Diggle P, Guttorp P, Fuentes M. Handbook of spatial statistics. 1st ed. Boca Raton: Taylor \& Francis Group; 2010.

52. Richardson S, Monfort C. Ecological correlation studies. In: Elliot P, Wakefield JC, Best NG, Briggs DJ, editors. Spatial epidemiology: methods and applications. Oxford: Oxford University Press; 2000. p. 205-20.

53. Wakefield J, Shaddick G. Health-exposure modeling and the ecological fallacy. Biostatistics. 2006;7:438-55.

54. National Mapping and Resource Information Authority (NAMRIA). Department of Environment and Natural Resources. 2018. http://www. namria.gov.ph/. Accessed 3 Feb 2018.

55. Prentice RL, Sheppard L. Aggregate data studies of disease risk factors. Biometrika. 1995;82:113-25.

56. Gelman A. Prior distributions for variance parameters in hierarchical models (comment on an article by Browne and Draper). Bayesian Anal. 2006;1:515-34

57. Gelman A, Carlin JB, Stern HS, Dunson D, Rubin DB. Bayesian data analysis. 3rd ed. New York: Taylor \& Francis Group; 2013.

58. Diggle PJ, Tawn J, Moyeed R. Model-based geostatistics. J R Stat Soc Ser C Appl Stat. 2002;47:299-350.

59. Thomas A, Best N, Lunn D, Arnold R, Spiegelhalter D. GeoBugs user manual. In: MRC biostatistics unit. 2004. https://www.mrc-bsu.cam.ac.uk/ software/bugs/thebugs-project-geobugs/. Accessed 18 Feb 2018.

60. Lunn D, Jackson C, Best N, Thomas A, Spiegelhalter D. The BUGS book: a practical introduction to Bayesian analysis. 1st ed. Boca Raton: Taylor \& Francis Group; 2012.

61. Brooks SP, Gelman A. General methods for monitoring convergence of iterative simulations. J Comput Graph Stat. 1998;7:434-55.

62. Gelman A, Rubin DB. Inference from iterative simulation using multiple sequences. Stat Sci. 1992;7:457-72.

63. Brooker S, Hay SI, Bundy DA. Tools from ecology: useful for evaluating infection risk models? Trends Parasitol. 2002;18:70-4.

64. Spiegelhalter D, Thomas A, Best N, Lunn D. WinBUGS user manual. In: MRC biostatistics unit. 2003. http://www.mrc-bsu.cam.ac.uk/bugs. Accessed 05 Feb 2018.

65. Spiegelhalter D, Thomas A, Best N, Lunn D. OpenBUGS user manual, version 3.0. 2. In: MRC biostatistics unit. 2007. http://www.openbugs.net/w/ Manuals. Accessed 05 Feb 2018.

66. Spiegelhalter D, Thomas A, Best N. OpenBUGS version 3.0.2. In: Downloads. 2018. http://www.openbugs.net/w/Downloads. Accessed 25 Jun 2018.

67. Sturtz S, Ligges U, Gelman A. R2OpenBUGS: a package for running OpenBUGS from R. J Stat Softw. 2005;12:1-16.

68. R Core Team. $R$ : a language and environment for statistical computing Vienna, Austria: R Foundation for Statistical Computing; 2013. https:// www.R-project.org/.

69. Hu Y, Bergquist R, Lynn H, Gao F, Wang Q, Zhang S, et al. Sandwich mapping of schistosomiasis risk in Anhui Province, China. Geospat Health. 2015:10:111-6.

70. Stensgaard AS, Vounatsou P, Sengupta ME, Utzinger J. Schistosomes, snails and climate change: current trends and future expectations. Acta Trop. 2019;190:257-68.
71. Kittur N, Binder S, Campbell CH, King CH, Kinung'hi S, Olsen A, et al. Defining persistent hotspots: areas that fail to decrease meaningfully in prevalence after multiple years of mass drug administration with praziquantel for control of schistosomiasis. Am J Trop Med Hyg. 2017;97:1810-7.

72. Rice science for a better world. In: International Rice Research Institute. 2018. http://irri.org/our-work/research/policy-and-markets/mappingrice-in-the-philippines-where. Accessed 22 Oct 2018.

73. Bauman PM, Bennett HJ, Ingalls JW Jr. The molluscan intermediate host and schistosomiasis japonica; observations on the production and rate of emergence of cercariae of Schistosoma japonicum from the molluscan intermediate host, Oncomelania quadrasi. Am J Trop Med Hyg. 1948;28:567-75.

74. Yang G-J, Utzinger J, Sun L-P, Hong Q-B, Vounatsou P, Tanner M, et al. Effect of temperature on the development of Schistosoma japonicum within Oncomelania hupensis, and hibernation of $O$. hupensis. Parasitol Res. 2007;100:695-700.

75. Pesigan TP, Hairston NG, Jauregui JJ, Garcia EG, Santos AT, Santos BC, et al. Studies on Schistosoma japonicum infection in The Philippines. 2. The molluscan host. Bull World Health Organ. 1958;18:481-578.

76. Gu Y, Brown JF, Verdin JP, Wardlow B. A five-year analysis of MODIS NDVI and NDWI for grassland drought assessment over the central Great Plains of the United States. Geophys Res Lett. 2007;34:L06407.

77. Kummu M, de Moel H, Ward PJ, Varis O. How close do we live to water? A global analysis of population distance to freshwater bodies. PLOS ONE. 2011;6:e20578.

78. Mari L, Gatto M, Ciddio M, Dia ED, Sokolow SH, De Leo GA, et al. Big-datadriven modeling unveils country-wide drivers of endemic schistosomiasis. Sci Rep. 2017;7:489.

79. VoPham T, Hart JE, Laden F, Chiang YY. Emerging trends in geospatial artificial intelligence (geoAl): potential applications for environmental epidemiology. Environ Health. 2018;17:40.

80. Mooney SJ, Pejaver V. Big data in public health: terminology, machine learning, and privacy. Annu Rev Public Health. 2018;39:95-112.

81. Lin Y, Chiang Y-Y, Pan F, Stripelis D, Ambite JL, Eckel SP, et al. Mining public datasets for modeling intra-city PM2.5 concentrations at a fine spatial resolution. In: Proceedings of the 25th ACM SIGSPATIAL international conference on advances in geographic information systems. Redondo Beach: ACM; 2017. p. 1-10.

82. Montresor A, Crompton DW, Hall A, Bundy D, Savioli L, et al. Guidelines for the evaluation of soil-transmitted helminthiasis and schistosomiasis at community level: a guide for managers of control programmes. Geneva: World Health Organ; 1998.

83. Burns CJ, Wright M, Pierson JB, Bateson TF, Burstyn I, Goldstein DA, et al. Evaluating uncertainty to strengthen epidemiologic data for use in human health risk assessments. Environ Health Perspect. 2014;122:1160-5

\section{Publisher's Note}

Springer Nature remains neutral with regard to jurisdictional claims in published maps and institutional affiliations.

Ready to submit your research? Choose BMC and benefit from:

- fast, convenient online submission

- thorough peer review by experienced researchers in your field

- rapid publication on acceptance

- support for research data, including large and complex data types

- gold Open Access which fosters wider collaboration and increased citations

- maximum visibility for your research: over 100M website views per year

At BMC, research is always in progress.

Learn more biomedcentral.com/submissions 